\title{
Uncertainty Management Associated With Project Scheduling in Mine Construction: A Coal Mining Case Study
}

\author{
Matt Renaud \\ McGill University \\ Mustafa Kumral ( $\square$ Mustafa.Kumral@mcgill.ca ) \\ McGill University https://orcid.org/0000-0003-1370-7446
}

\section{Research}

Keywords: mine construction, Monte-Carlo sampling, coal mining, uncertainty management, risk quantification, linear programming

Posted Date: December 28th, 2020

DOI: https://doi.org/10.21203/rs.3.rs-132763/v1

License: (c) (i) This work is licensed under a Creative Commons Attribution 4.0 International License.

Read Full License 


\title{
Uncertainty Management Associated with Project Scheduling in Mine Construction: A Coal Mining Case Study
}

\author{
Matt Renaud and Mustafa Kumral \\ Department of Mining and Materials Engineering, McGill University \\ 3450 University Street, Montreal, Quebec, H3A 0E8, Canada \\ Corresponding author: mustafa.kumral@mcgill.ca \\ Tel.: +1-514-398-3224 \\ Fax: +1-514-398-7099
}

\section{Abstract}

Due to the cyclical nature of commodity prices, the profitability of mining projects relies on proper timing. To ensure optimal profits, mines should be brought online at the time, which maximizes the potential value of the asset. In this paper, a coking coal mine construction case is used to demonstrate the effectiveness of scheduling large-scale construction projects with uncertain durations under price cyclicality. Project parameters are obtained stochastically via Monte Carlo sampling, allowing for the influence of uncertainty to be quantified. The critical path method and linear programming are employed to analyze the results and to optimize the construction process, ensuring the maximum value of the mining project. The parameters are repeatedly sampled to obtain distributions of possible project outcomes, allowing for risk and sensitivity quantification. The optimal schedule for construction was determined to be 247 weeks, with a most likely value of $\$ 813$ million.

Keywords: mine construction; Monte-Carlo sampling; coal mining; uncertainty management; risk quantification; linear programming 


\section{Introduction}

Mining greenfield projects, due to their enormous size and complexity, have numerous factors affecting timing, cost, and value (Brahm \& Tarziján, 2015). Constantly changing commodity prices, geological uncertainty, production delays, and even exchange rates can drastically alter the outcome of a mining venture. Of these risks, economic uncertainties affecting the profit margins for commodities pose the most significant threat to a mining project (Haque, Topal, \& Lilford, 2016). Unfortunately, because these factors tend to be external in nature, it can be very difficult to effectively mitigate the resulting risks. Mining companies can adjust their practices to produce more cheaply or efficiently but cannot control market conditions and thus are very susceptible to significant changes (Trench \& Sykes, 2014). Consequently, it is challenging to accurately value a mining project in the pre-production phase; mining projects that are incredibly profitable at current commodity prices may struggle to break even just years later. Nonetheless, the valuation of a potential project is of utmost importance, allowing for options to be considered and the optimization of investment to be achieved (Sabour \& Wood, 2009).

A valuation can be completed on a broad spectrum of complexity with similarly varying success. The base case for a project valuation requires simple estimations that are treated as fixed parameters. These estimations can be adapted from previous experience, sample evaluation, expert consultation, or even pilot testing. However, these estimations hold no guarantee of truth, and provide no quantitative consideration of uncertainty, often leading to discrepancies between plans and outcomes and undervaluation of projects (Botin, Del Castillo, \& Guzman, 2013) (Del Castillo \& Dimitrakopoulos, 2014). To properly represent the value of a mining project, risks must be quantified. These risks can be categorized based on how they will affect the project outcome; risks can either be external (affecting the outcome of the project regardless of how it is handled) or internal (affecting the performance of the project itself) (Botin, Del Castillo, \& Guzman, 2013). For mining projects, external risks include commodity prices, social/political climate, licensing, and regulation, whereas internal risks include geological, temporal, process, and cost uncertainties (Del Castillo \& Dimitrakopoulos, 2014; Zhang, Nieto, \& Kleit, 2015). 
52 Thus, with so many uncertainties, it is evident how simple estimates fail to account for project risk 53 adequately.

54 Typical risk mitigation efforts come in the form of stochastic price forecasting, but commodity

55 prices are impossible to accurately and precisely predict. Trends for commodity prices (base metals in

56 particular) tend to follow cyclical periods of highs and lows, but the periods are rarely uniform in length.

57 While some methods exist to quantify volatility (Haque, Topal, \& Lilford, 2016), commodity prices can

58 often be expected to stray significantly from initial estimates (Sabour \& Wood, 2009). Starting mine

59 construction in down periods on the assumption of a coming price increase presents an unacceptable risk

60 for resource companies and their investors. It is critical, thus, that mining projects are timed properly.

61 Under ideal conditions, a mining project will start to produce on the upswing of a commodity price cycle.

62 To achieve this, mine construction must be rigorously scheduled and monitored. Even if prices are

63 expected to increase in the near future, delaying production could result in a lower present value of the

64 project. This paper aims to evaluate a large-scale coal mining project for the optimization of decision

65 making during the construction scheduling process. The effects of temporal uncertainty will be

66 demonstrated to allow for optimization of activity scheduling and resource allocation using the critical

67 path method and Monte Carlo sampling-based linear programming.

2. Literature Review

Past studies have explored a variety of risk factors for mining projects as well as ways to both mitigate and quantify the effects of uncertainty. Among the most common and perhaps the most critical

71 uncertainties to be considered for mining production are uncertainties associated with commodity prices.

72 Sauvageau \& Kumral (2018), Sabour \& Wood (2009), and Haque, Topal, \& Lilford (2016) examined the

73 effects of volatility for commodity prices and exchange rates using stochastic price simulation and real

74 options valuation (ROV). Similarly, Dimitrikopoulos \& Sabour (2007) used a simulation-based ROV

75 method to evaluate fixed schedules for mine extraction to aid decision making under uncertainty. Zhang,

76 Nieto, \& Kleit (2015) applied mean-reverting processes to commodity pricing as well as ROV to 
77

determine the value of flexibility and optimal extraction schedule of mineral commodities. Muniappen and Genc (2020) investigated the performance of a coal mining system through dynamic simulation to evaluate a mine life extension project. The majority of the literature for dealing with financial uncertainty in the mining industry is applied to commodity prices and how management can efficiently react to changes to future market conditions. As demonstrated by Zhang, Nieto, \& Kleit (2015) and Trench \& Sykes (2014), significant value can be achieved by timing mineral extraction properly. In the timing context, Ugurlu and Kumral (2019) quantified the relationship between cost and timing of drill bit replacement in a coal mining operation using Monte-Carlo simulation.

Similar to this paper, uncertainty management attracted significant attention because delay costs in the construction industries can reach massive amounts quickly. Unspecific to mining, construction scheduling research has been thoroughly explored in the past, with main focuses including duration uncertainty and scheduling under unpredictable circumstances (Zhou, Love, Wang, Teo, \& Irani, 2013). Martens and Vanhoucke (2017) proposed a different approach to project management in the construction industry based on reacting and correcting unexpected events throughout the project management. Other studies have employed a variety of optimization models to construction scheduling problems such as simulated annealing (Azaron, Sakawa, Tavakkoli-Moghaddam, \& Safaei, 2007, König \& Beißert, 2009), ant colony optimization (Xiong \& Kuang, 2008), particle swarm optimization (Guo, Zhu, Ding, \& Li, 2010), neural networks (Adeli \& Karim, 1997), and genetic algorithms (Guo, Zhu, Ding, \& Li, 2010; Eldin \& Senouci, 2004; and Calp \& Akcayol, 2018). A comprehensive compilation of methods of scheduling optimization and their respective successes and failures can be further explored in (Zhou, Love, Wang, Teo, \& Irani, 2013; Lau \& NG, 2013). The projects described by these studies are all of the different types but are all similar in the sense that they represent engineering construction projects, and are all projects that can be broken down into individual activities related to each other by precedence constraints. As such, the proposed method could be applied to any of these projects in place of the methods used in the previous literature. 
While these explored methods have been proven to improve the value of construction projects by optimizing various aspects such as cost, timing, and resource allocation (often at the same time), the

104 methods can be difficult to implement and are often not well understood by both the general public and

105 typical project management personnel. In 2008, the Chartered Institute of Building completed a

106 comprehensive survey of over 2,000 construction projects, revealing some troubling shortfalls in the

107 construction industry. Among other problems, fewer than $10 \%$ of projects surveyed indicated familiarity

108 with complex scheduling software (with the most common method of scheduling, being a simple bar

109 chart), while a further $10 \%$ reported no software used at all, and over $90 \%$ of respondents calling for

110 increased education and training for project scheduling (Chartered Institute of Building, 2008). The study

111 clearly displayed a lack of utilization for improvement methods that have been made available for

112 decades, despite proven motivation in the form of increased value or efficiency. This suggests that the

113 available methods are prohibitively complex and/or require resources that are not commonly available to

114 construction firms.

The originality of this paper resides in the creation of a method which has the capacity to

116 optimize the construction scheduling process for maximum value under the effects of temporal

117 uncertainty, using tools and concepts with widespread availability and simplicity. The proposed method is

118 based on a stochastic approach and will apply CPM and Monte-Carlo based-LP to mine construction

119 planning to determine efficient resource allocation while optimizing project value in such a way as to take

120 into account the effects of unexpected realizations of variables. Thus, mine management will have range

121 possible outcomes regarding the project value and timing. If this range does not coincide with the risk

122 perception of the management, a risk mitigation strategy can be implemented. This paper is an extension

123 of our previous work (Renaud \& Kumral, 2020) and takes a further step that incorporates uncertainties 124 into the project planning procedure. 
126

127

128

129

130

131

132

133

134

135

136 137 given by:

138

139

140

141

142

\subsection{Model Basis}

The mine construction project is displayed by a network diagram (see Appendix 1.4) where nodes represent individual activities to be completed, and links (arrows) represent precedence relationships between activities. Activities are divided into certain and uncertain categories. Certain activities are those whose duration can be predicted with a reasonably high degree of accuracy, and it follows that uncertain activities are those whose duration cannot be accurately predicted. Uncertainty in activity duration is handled stochastically; each uncertain activity is given a random duration value from a PERT probability distribution, special case of the beta distribution, that takes three parameters: a minimum, maximum, and most likely (mode) . To obtain the distribution, which is a modified beta distribution, activities' optimistic $(a)$, pessimistic $(b)$, and most likely $\left(t_{\text {mode }}=s\right)$ durations are estimated with the addition of a scale parameter $\lambda$ (which decides the height of the distribution). The mean $(\mu)$ and the standard deviation $(\sigma)$ is

$$
\begin{aligned}
& \mu=\frac{a+b+\lambda s}{\lambda+2} \\
& \sigma=\frac{(b-a)}{6}
\end{aligned}
$$

and the parameters $v$ and $w$ (which dictate the shape of the distribution curve) are calculated as:

$$
\begin{aligned}
& v=\frac{(\mu-a)(2 s-a-b)}{(s-\mu)(b-a)} \\
& w=\frac{k(b-\mu)}{(\mu-a)}
\end{aligned}
$$

The distribution gives the density function:

$$
f(x)=\frac{x^{s-1}(1-x)^{t-1}}{B(v, w)}, 0 \leq x \leq 1
$$


Values for uncertain activity durations are sampled randomly from the probability distribution shown in equation (5). Sampling the distribution for each uncertain activity using their respective

147 estimation parameters (a, b, and s), provides a simulation of the project representing one possible 148 outcome. By simulating all activities many times, a life distribution of project outcomes is created. The 149 distribution of outcomes allows for optimistic, pessimistic, and most likely estimates for the project 150 schedule at a fixed cost, or project cost (and/or value) at a fixed duration (depending on the distribution 151 created). The number of iterations simulated is flexible (any value can be input), so it is left to the 152 discretion of the user (scheduler/project management team) to balance accuracy of results with calculation 153 time.

The Critical Path Method (CPM) is used to evaluate the project network as well as scheduling risk for individual activities. The CPM algorithm (the intricacies of which are widely published) first calculates the earliest start (EST) and finish times (EFT) of each activity in a "forward pass" and then 157 calculates the latest start (LST) and finish times (LFT) of each activity in a "backward pass". The slack time or "float" is given by the difference of LST and EST, which represents the allowance for the delay in completion for each activity. Activities with a float of zero are considered "critical activities" as any delays to these activities would also delay the completion of the project. After all iterations of the simulation are complete, the likelihood (percent chance) of any activity being critical (on the longest path 162 through the network) can be calculated by counting the number of simulations where the activity in 163 question has zero slack time available. As activity duration estimates change, different activities may 164 dictate the earliest start time of others, changing the critical path. Critical activities carry the most risk, as 165 their performance has a direct impact on the final outcome of the project; thus, it is an important 166 consideration for project management. time and cost for each activity. The idea behind this relationship is that an activity can be expedited by increasing the amount of resources (money) available. This action is known as "crashing" an activity. For 
example, suppose a team of four people work eight hours per day to achieve a task in four weeks.

171 Perhaps, if they were to work 12 hours per day, the task can be achieved in only three weeks, but, since

172 workers are now working extra hours, they must be paid overtime for their efforts. Now, the labor cost

173 has risen to $131 \%$ of the original scenario, but the duration has been reduced to $75 \%$ of the original. Next,

174 consider the addition of three more workers working overtime to further reduce the duration by another

175 week. The additional cost for extra workers per unit decrease in duration will be more expensive than the

176 initial improvement due to overtime pay. These successive cost-time relationships are known as "crash

177 levels". Each crash level is a linear relationship between the dependent and independent variables (cost

178 and time, respectively) that exists on a finite domain (increasing resources at a specific incremental cost

179 can only reduce duration so far before becoming more expensive). For a project with a fixed duration and

180 uncertain base case activity durations, critical activities must be crashed in order to meet the specified

181 deadline. The following section will describe how to handle crashing activities to maximize value.

\subsection{Monte Carlo Sampling-Based Linear Programming Model}

A Monte-Carlo sampling based Linear Programming model (MCS_LP) was implemented to optimize project simulations. The simulation can be conducted (estimating project outcomes) in two ways: fixed cost and fixed duration (cost or duration are the independent variables, respectively). For the fixed cost version, every activity is assigned a sampled duration (from the distribution described in the previous section) based on a base case fixed cost (estimated from various sources). In the fixed duration section, a distribution of possible costs is created by applying the linear programming model to the activity duration estimates. Since each activity's duration will be different in each iteration, critical activities need to be crashed (increased cost for the decreased duration) to satisfy the fixed project

192 at the minimum possible cost. By repeating the process for a variety of fixed durations, an informed 193 decision can be made by the project management team for both deadline selection and resource allocation. 194 Similar to the previous section, the probability of criticality for each activity under crashed conditions is 
195 still displayed, allowing for individual risk of activities to be monitored. The formulation of the LP model 196 uses the following notation:

$197 i=$ activity number $(i \in \mathbb{N})$.

$198 n=$ crash level $(n \in(A, B, C))$.

$199 m=$ total number of activities $(m \in \mathbb{N})$.

$200 j_{i}=$ available crash levels for activity $i(j \in(A, B, C))$.

$201 T_{i}=$ base case duration for activity $i$.

$202 t_{\text {in }}=$ crashed duration of activity $i$ at crash level $n$.

$203 C_{T i}=$ base cost of activity $i$.

$204 c_{\text {tin }}=$ cost of activity $i$ crashed at level $n$.

$205 x_{\text {in }}=$ time reduction for activity $i$ at crash level $n$.

$206 l_{i, i \prime}=\operatorname{lag}$ time for link joining activity $i$ and activity $i^{\prime}$.

207 As activities are crashed, the decrease in duration is a result of an increase in cost. The relationship

208 between the two parameters for activity $i$ at crash level $n$ is given by:

$$
\tilde{g}_{i n}=\frac{C_{t i n}-C_{T i}}{T_{i}-t_{i n}}
$$

210 Cost $k$ for each activity $i$ is given as the base case cost combined with the sum of crash costs incurred:

$$
k_{i}=C_{T i}+\sum_{n=A}^{j_{i}}\left(g_{i n} x_{i n}\right)
$$

212 Note that $\sum_{i=0}^{i} C_{T i}$ is a constant, so to optimize the project cost, the objective function is simply:

$$
\operatorname{Min} Z=\sum_{i=1}^{m}\left(\sum_{n=A}^{j_{i}}\left(\tilde{g}_{i n} x_{i n}\right)\right)
$$


214 Constraints for the LP model are implemented to preserve precedence relationships. The use of an 215 auxiliary variable $y_{i}$ (representing the EST for each activity $i$ ) helps to formulate the following constraint 216 for each activity $i$ and succeeding activity $i$ ':

$$
y_{i}+\left(T_{i}-\sum_{n=A}^{j_{i}} x_{i n}\right)+l_{\left(i, i^{\prime}\right)} \leq y_{i}^{\prime}
$$

Many activities have multiple predecessors with different finish times. It follows then that only one of the activities would dictate the earliest start time for the next activity. However, since activities' durations can be changed by employing CPM crashing, every link between preceding and succeeding activities must be represented with a constraint such as the one in eq. 9 to preserve the relationships in the LP model. Then, since each crash level exists over a finite domain, the reduction instances for each activity $i$ and crash level $n$ are restricted by:

$$
x_{i n} \leq t_{i(n-1)}-t_{\text {in }}
$$

Finally, all variables are assigned a nonnegativity constraint as each activity cannot take longer than its base case and activities cannot have a start time before the start of the project:

$$
y_{i}, x_{i n} \geq 0
$$

Please note that this formulation was developed for a previous study written by the same authors of this paper. The previous study used a similar formulation to determine optimal scheduling of a mine construction under price cyclicality without considering uncertainty. This study can be considered as a continuation and/or an improvement to the previous study to expand the capabilities of the model and address issues that are more pertinent to the construction industry as a whole. Please refer to the previous study for further details and intricacies of the linear programming formulation (Renaud \& Kumral, 2020). Depending on which aspects of planning are fixed (i.e., project cost or duration), the next step is completed in different ways. First, for a fixed cost (using the base case cost estimates), multiple iterations of the CPM/ MCS_LP combination produce a distribution of project durations. Note that the number of 
237 iterations is left up to the scheduler; without LP, the script runs almost instantaneously. With LP, the

238 duration is significantly slowed, but should scale of the project cause the script to exceed time

239 requirements of the scheduler, projects could easily be broken down into sub-problems for quicker

240 optimization. This is achieved in the proposed model by employing a simple Visual Basic script to

241 complete the following steps (see Appendix 1.2 for the employed script):

242

243

244

245

246

247

248

249

250

251

252
1. Clear data from previous simulations.

2. Sample the probability distribution for each uncertain activity to provide a duration estimate.

3. Enter duration simulation results for all 80 activities into the CPM algorithm sheet.

4. Determine project duration and criticality of activities (using the CPM algorithm).

5. Record activity slack times and project duration in a results table.

6. Repeat steps $2-5$ for the specified number of iterations $(2,000$ by default, but more or less can be specified by the user).

To determine these numbers, we gradually increased the number of iterations until the results were stabilized.

Next, by fixing the project deadline, a life distribution of project cost and the present value is produced.

As for fixed cost, the script completes many iterations according to the following steps:

1. Clear data from previous simulations

2. Sample the probability distribution for each uncertain activity.

3. Enter duration simulation results into the LP model.

4. Crash select activities (using the LP model) to ensure deadline compliance.

5. Enter crashed activity durations into the CPM algorithm.

6. Determine the criticality of crashed activities via CPM.

7. Record project cost, NPV, and activity slack times in a results table. 
8. Repeat steps 2-7 for a specified number of iterations (500 by default as the LP model takes significantly more time than simply employing the CPM algorithm).

262 The code for the described script can be found in Appendix 1.2.

For both simulation options, some extra factors must be defined. While it is useful still to

264 compare project costs between different outcomes, the project's present value provides a much better

265 indicator of success. Due to the cyclical nature of commodity prices, the project option that takes much

266 more time at a lower cost will not necessarily provide the best value. Thus, to examine project value

267 during the simulations, some assumptions about the mine must be made. In practice, these assumptions

268 would be legitimate parameters that are project-specific, but to prove effectiveness, the factors will be

269 estimated, as explained in the following section.

\section{Case Study}

To demonstrate the proposed model and its benefits, it will be applied to the construction plan of

273 a large-scale mountaintop metallurgical coal mine. Metallurgical coal mines could benefit significantly

274 from the proposed scheduling method, as price trends for this commodity closely follow cyclical trends of

275 supply and demand from emerging economies (Connolly \& Orsmond, 2011). The network diagram of

276 this case study is given in Appendix 1.4. At the start of the project, the land for the mine is owned by

277 major resource company a Commodity Mining Corporation (CMC) and is located adjacent to currently

278 operating successful coal mining operations also owned and operated by CMC. The new mine will be

279 constructed in such a way to make use of the existing tailings facility of an adjacent project; thus, the

280 construction costs of tailings management facility are not included in the construction plan. The land,

281 while yet undeveloped, is in a stable political jurisdiction and CMC is on good standing with the

282 surrounding communities after providing employment opportunities, sponsorships, and education to

283 residents. Note that any project parameters included in this analysis do not represent any particular mine 
currently or previously in existence. A more in-depth description of the project and its assumptions can be found in the preceding study (Renaud \& Kumral, 2020).

The proposed model is built to accept a wide variety of inputs for various parameters, including commodity price, operating expenditure, capital expenditure, production rates, the life of mine, and the cost of capital. This is accomplished thanks to the simplicity of the excel model. Simply labelled input points allow for user-contributed parameters for use in the model. As such, the model allows for any input as needed by the user. It should be noted as well that the model can be used outside of the mining context. For this case study, the commodity price schedule represents the benefit to the project of adhering to a specific deadline or schedule, but for the general use of the model, this input can be replaced by another project-specific benefit for punctuality. Similarly, production rates and life of mine inputs allow for further quantification of the value of schedule compliance. Finally, operating and capital expenditures, as well as the cost of capital, are common and can be applied to any project.

In reality, these parameters will vary from project to project as a result of the sociopolitical and

297 physical environments, and best practice would dictate the involvement of project stakeholders to develop 298 initial estimates (such as production rates, the life of mine, and cost of capital). For this case study, 299 however, assumptions will be made using a variety of sources to use the described method. Note that the 300 proposed model could accept stochastic estimation methods for all the parameters described above; 301 however, more iterations may be required, and, as more probability distributions are involved, each 302 iteration of the simulation will take more time to complete. In practice, there would be sufficient time to 303 run lengthy simulations for the benefit they provide, but, as a proof of concept, this paper will fix parameters deterministically as described in the following paragraph.

The mine to be constructed is fairly large, with 50 million tonnes of proven metallurgical coal reserves. The planned production rate is based on the maximum capacity of the railroad, producing five 307 million tonnes per year (giving a mine life of ten years). The rate is assumed to be constant over each 308 year's quarters (1.25Mt each quarter) and for all ten years of production for the sake of simplicity. Rather 
than estimating a commodity price schedule, the historical price chart will be used. The construction project is slated to start in Q3 2005. Operating expenditures (mining/processing/transportation costs) are 311 estimated to average at $75 \mathrm{USD} /$ tonne, and both operating and capital costs are discounted at a $12 \%$ cost 312 of capital. It is important to note that the case for a real mine would be different than many of the 313 assumptions made in this paper. Proven reserves are often expanded as the mine ages. Stockpiling 314 strategies are developed to weather low price periods. Operating costs may rise or fall as equipment ages, 315 stripping ratios change, and haul profiles expand or contract. Especially, mounting and maintenance costs, 316 and inspection intervals associated with mining assets have significant effects on project management 317 (Golbasi and Demirel, 2017). These cases represent the sources of risk not addressed quantitatively by 318 this paper. The construction process is broken down into 80 individual activities (with the addition of two 320 milestones or zero-duration "dummy" activities for the start and finish points). The 80-activity network 321 covers all aspects of a mine construction project, including (but not limited to) permitting, planning, 322 exploration, testing, equipment procurement, financing, facility construction, and even overburden 323 removal. At the time construction process is considered complete (the finish milestone), productive 324 mining (moving/processing/selling coal) can start. The goal of the proposed method is to determine either 325 when mining can start or how much it would cost to start mining by a specific time (for this case study, 326 the specific time is explored by fixing different quarters to the end period such that different scheduling 327 options can be compared). Combining both with the price schedule, it is shown which plan holds the 328 highest value, and which parts of the project carry the most risk. A full list of activities, their base-case 329 durations (most likely PERT estimate), and their predecessors can be found in Appendix 1.1. Often, megaprojects fail to properly consider resource availability when planning for activity costs or, worse still, they fail to consider individual activity cost all together (Chartered Institute of 332 Building, 2008). For this case study, estimations of cost and duration are completed using various 
sources $^{1}$ as well as some personal experience of the authors to mimic best practices. However, costs are

334 aimed to be justified from a published source as much as possible. For example, activities whose costs

335 result from equipment operation are estimated based on hourly costs applied to the activity duration. All

336 equipment used in the construction/development process is assumed to be purchased new, and

337 procurement and operating costs for equipment are based on the estimates provided by CostMine's Mine

338 and Mill Equipment Cost Estimator's Guide (InfoMine USA, Inc., 2016). Also included in activity cost

339 estimates are personnel costs for labor, planning, and management from various sources ${ }^{3}$ as well as

340 auxiliary costs such as software licenses and travel/delivery expenses. For CPM analyses, Weaver (2011)

341 recommends an efficiency factor be added to cost estimates to help account for various biases; thus, base

342 cost estimates for the case study are modified by a factor of 1.2. Causes and effects of these biases will be

343 described in the Limitations section of this paper. A more in-depth description of the cost estimation

344 process can be found in the previous study (Renaud \& Kumral, 2020).

[Insert Fig. 1 here]

\footnotetext{
${ }^{1}$ Activity cost/duration information adapted from: (Access Consulting Group, 2008) (Canadian Institute of Mining, 2011) (InfoMine USA, Inc., 2016) (Kenneth P. Green, 2017) (Kihn, 2015) (National Native Title Tribunal, 2009) (National Resources Canada, 2006) (PayScale, Inc., 2018) (Smith, 2014) (U.S. Securities and Exchange Commission, 2016)
} 
Next, project durations are fixed on a quarterly basis. The lowest deadline option considered was 357 determined to be 4.75 years (247 weeks), because, at this deadline, approximately $15 \%$ of simulations 358 were deemed unfeasible (crashing every possible activity to its maximum could not reduce the simulated 359 duration to 247 weeks). It should be noted that this is a limitation specific only to this case study. The 360 formulation of the mine construction problem (namely the possible crash levels) forms the boundaries of 361 the schedule outcomes. For general use, similar feasibility issues will be encountered based on the 362 project-specific constraints of the project to which the method is applied. Similarly, the scalability of this 363 method is of no particular concern, as the project being analyzed can be broken down and each part 364 analyzed separately with no loss of optimality. The maximum considered was 5.5 years (286 weeks), as nearly all simulations set to 5.75 years provided a lower value than the 286 -week deadline. The deadline 366 that provided the highest value was found to be 4.75 years; the results (NPV) of 500 simulations for the 367 4.75-year (247-week) deadline are shown in Fig. 2. The most common simulation result for the 247-week 368 project was $\$ 813$ million, with a minimum value of $\$ 733$ million and a maximum value of $\$ 913$ million. 369 The average value is approximately $\$ 794$ million, with a median value of $\$ 790$ million. The standard 370 deviation of NPV is $\$ 5.14$ million. The value of the project limited to 247 weeks can be predicted 371 between $\$ 750$ million and $\$ 850$ million at $95 \%$ confidence. Note that while 247 weeks provided the 372 highest average, median, and mode, it was shown to be unfeasible for a significant portion (15\%) of time, 373 even at the maximum possible cost (all activities at crash point). However, allowing the project deadline 374 to extend another quarter (5-year/260-week deadline) not only reduces the average value by over $\$ 20$ 375 million, it also reduces the maximum possible value by nearly $\$ 100$ million (although the minimum 376 possible value is approximately equal to the 247 -week option). Thus, it is determined that the project 377 management should aim for project completion in 247 weeks and allocate resources to critical activities 378 accordingly. The standard deviation of the project completion is 8.94 weeks. The activities with a $100 \%$ 379 chance of criticality at 247 weeks (with the exception of activities "Mining Method Planning" and 
“Production Rates \& Targets" were critical in 97.4\% of simulations). Activity 206 ("Mining Transport

381 Planning") and Activity 10 ("Stripping 2") are critical in 58.6\% and 11.8\% of simulations, respectively.

382 Activities with $100 \%$ criticality represent those most sensitive to delays, and those that carry the most

383 risk. Note that in the case of criticality for activity 10, there exist two critical paths, as activity 10 and 11

384 will have the same duration and occur simultaneously.

Note as well that the distribution of project values for the 247 -week deadline is unbalanced. This situation is due in part to the unfeasible results providing the lowest values (all activities fully crashed with a delayed revenue commencement) and in part to the activity crashing structure. Without the unfeasible results, the left side (lower values) would be more sparse, showing mainly outliers, similar to 1.3). As shown in the fixed cost section, a 247 -week deadline is unlikely to be reached without activity crashing. This results in an imbalance in activity values where outliers without (or with minimal) crashing prove to be worth far more than those that require higher percentages of crashed activities. Furthermore, many activities whose crash costs are proportionally lower occur earlier in the construction process, meaning that their influence is more significant than similar crash costs later in the project (for example, speeding up site planning by one week is much cheaper than increasing the rate of overburden removal).

396 This results in "bunching" of values, where many successive iterations of crashing only change the 397 project value slightly, despite reducing the duration significantly. For these reasons, a larger concentration 398 of results provides lower value, and there exists a natural drop-off where little to no crashing is employed.

399 Results from sub-optimal deadlines can be found in Appendix 1.3.

\subsection{Limitations}

The proposed method is not without its flaws. Whenever estimations are used to determine project parameters, various biases will influence the results. Estimations for cost and time are nearly always optimistic (Weaver, 2011), and even though duration estimates are determined stochastically, the 
initial estimates to create the PERT distribution carry their own biases. The most influential of these are optimism bias, expectation bias, and the human tendency to be self-serving. Optimism bias can be described simply as the tendency for humans to underestimate resources (time/cost) necessary to achieve a goal, even if that goal had proven itself to be more costly in the past. This is especially evident when recalling the personal experience, as people tend to block out or diminish negative memories and favor those where success was achieved, regardless of the circumstance (Taylor, 1991). Expectation bias refers 411 to the propensity for a scheduler to choose or accept estimates that most closely resemble their goal. For 412 example, if a manager expects an activity to take two weeks and cost $\$ 50,000$, they are far more likely to accept a contractor who says they can complete the activity for $\$ 48,000$ in 15 days than a contractor who says it is not possible to finish the activity in fewer than three weeks with fewer than $70,000 \$$, even if the second contractor is correct. Any estimate that allows the goal to be attained more easily will be chosen over one that does not, even if both are equally likely (Shepperd, Malone, \& Sweeny, 2008). Similarly, a

417 scheduler is more likely to present a schedule or plan to his management that is cheaper and faster as it makes them look better to their superiors or appear more competent. This effect is very evident in 419 contractor estimates, as the expectation bias described previously would dictate that the contractor with 420 the cheapest bid would be the one to receive the job (Espinoza R. D., 2011). The cumulative effect of 421 these biases often presents a plan rife with unwarranted optimism. While optimism is generally 422 considered detrimental when an accurate and precise estimate is required, an optimistic schedule often has 423 a motivating effect on the development teams. However, the increased risk presented by an unrealistic 424 schedule is unlikely to be offset by the increased motivation (Weaver, 2011). 
critical path, and the only risk quantification presented is the slack time for individual activities or paths.

431 The proposed model gives some insight as to which paths or activities are more likely to be critical

432 through the stochastic duration simulations by presenting a probability of criticality for each activity. A

433 more thorough quantification of risk could be achieved by the use of the Program Evaluation and Review

434 Technique, whose algorithm presents a likelihood of any path being completed in the given deadline

435 (Hillier \& Lieberman, 1986). Furthermore, simply examining the present value of certain decisions can

436 lead to other problems. Ideally, the LP model should output a schedule that provides the maximum

437 present value. To achieve this, however, activities should be scheduled as late as possible to delay

438 spending (allowing for lower discounted costs). By doing this, however, every activity becomes "critical"

439 as all the slack time has been consumed before the capital is employed. This situation is not an acceptable

440 risk, clearly, as now any delay in any activity will directly affect project performance. Thus, the model

441 accounts for this effect by assuming all costs are incurred at the EST. Unfortunately, this means the result

442 is not truly optimized, as delaying the start of some activities by consuming slack time could provide

443 slightly higher value with increased risk. The value/risk trade-off is a decision that must, therefore, be

444 considered by management on a case-by-case basis. This model simply demonstrates the outcomes of

445 various schedules, providing flexibility for increased resource efficiency.

The decision-making process for the proposed model uses a traditional discounted cash flow

447 (DCF) method to compare the value of different scheduling scenarios. DCF valuation is widely used due

448 to its ease of implementation and relatively low barrier to entry (Hall \& Nicholls, 2007). However, it is

449 becoming increasingly evident that DCF valuations fall somewhat short of reality; the value associated

450 with the ability to react to changing parameters and change plans based on various options is not properly

451 captured by the standard DCF method (Hall \& Nicholls, 2007) (Sabour \& Wood, 2009) (Botin, Del

452 Castillo, \& Guzman, 2013) (Samis, Martinez, Davis, \& Whyte, 2012). A study by Samis, Martinez,

453 Davis, \& Whyte (2012) describes three main limitations of the DCF method as the ignorance of

454 randomness for cash flow contributors, the ignorance of financial effects of flexibility, and the ignorance 
of changes of risk over time. The first shortcoming can be mitigated somewhat through a Monte Carlo

456 simulation, as completed in the proposed model. Since not every variable has been simulated, this

457 criticism remains valid, but it should be noted that the model can accept simulated values for every input

458 if the user wishes to do so. The second criticism of DCF is similarly valid for the proposed model.

459 Changes to an initial plan are nearly inevitable, especially for large-scale complex projects such as mine

460 construction. The ability to revise decisions based on changes in various parameters or other information

461 not previously available (such as new technology) carries a significant value (Sabour \& Wood, 2009)

462 (Hall \& Nicholls, 2007). The undervaluation associated with the DCF method should not be ignored, but

463 it should be noted that its effects could be muted when combined with the optimism described in previous

464 paragraphs. The third shortcoming of the DCF method is perhaps the most important but is one that can

465 be incorporated into the proposed model. Changes to risk over time can be simulated by developing the

466 risk profiles of each parameter used in the valuation. As the project continues, any deficiencies or

467 proficiencies from the earlier stages can be included in the model, and their effects over time can be

468 quantified. The proposed model, while simple, can be used at any point in the process to aid in making

469 changes to initial plans or changing decisions. The strength of the model is its proficiency in providing a

470 clear valuation of a wide range of possibilities moving forward from the present time; a task at which

471 DCF excels (Espinoza \& Morris, 2013). Note that a Real Options Valuation could be applied to this

472 model by incorporating the value of the DCF shortcomings, but this may risk reducing the ease of access

473 and simplicity of this method-one of the primary strengths and reasons for implementation. This

474 sentiment was confirmed by Ampofo (2017), who surveyed mining professionals and concluded that a

475 combination of lack of education, trust, and access to software had prevented implementation of such

476 methods in the mining industry in the past.

477 5. Conclusions

478 To maximize the value of a potential mining project, commodity price cyclicality must be 479 considered along with various uncertainties associated with project parameters. Mines must be brought 
online at the right point in a price cycle to produce maximum profit. To achieve this, mine construction

481 projects should be scheduled to take advantage of the positive swings in price cycles. The proposed model

482 achieves this through the use of CPM and LP to determine the value of different plans or project

483 outcomes. In the case study, a large-scale open-pit metallurgical coal mine is paired with a historical price

484 schedule. At the base case cost, a life distribution of durations is produced, allowing management to

485 explore the potential for success at a minimum cost. Next, various fixed deadlines are explored, and

486 distributions of their value are produced. It is determined that the coal mine should have a set deadline of

4874.75 years, providing an average value of $\$ 794$ million and a most likely value of $\$ 813$ million. At the

488 base case cost, the most likely outcome for mine construction duration is found to be 275 weeks (giving a

489 project value of $\$ 656$ million).

Continuations to this study may include incorporation of more randomized variable estimation.

491 While the method allows for a wide variety of parameters to be modeled stochastically, activity duration

492 was the only non-deterministic variable. As more variables are calculated from probability distributions, a

493 more accurate representation of the outcome of mine construction projects can be realized. It should be

494 noted, however, that applying stochastic estimation to more aspects of the plan will require more

495 simulations and more computation time. This improvement could help mitigate the effects of optimistic

496 bias on parameter estimation to give a more realistic valuation. Similarly, a real option valuation (ROV)

497 could be applied to supplement the DCF valuation used in this study. An ROV would help to quantify the

498 value of flexibility and help further prove which schedule provides the maximum value. This would also

499 improve the ability of a management team to mitigate possible risks in the construction process. It should

500 be noted, however, that the option with the highest ROV is not necessarily the best design option

501 (Dimitrakopoulos \& Sabour, 2007). Finally, this model could be applied to fields other than mining, as it

502 is designed to optimize the scheduling of long-term complex projects with multiple inputs. While a mine

503 construction project is sufficiently complex and uncertain to demonstrate the effectiveness of the 
504 proposed model, it is not limited to mining applications, but rather can be applied anywhere there exists 505 multiple activities with complex precedence relationships.

506

507

6. Acknowledgement

508

This work was supported by the Natural Sciences and Engineering Research Council of Canada

509 (NSERC) (Fund number: 236482). The authors thank for these support.

510 


\section{References}

Access Consulting Group. (2008). Stage 1 Construction Site Plan. Carmacks: Access Consulting Group.

Adeli, H., \& Karim, A. (1997, December). Scheduling/Cost Optimization and Neural Dynamics Model for Construction. Journal of Construction Engineering and Management, 123(4), 450-458. https://doi.org/10.1061/(ASCE)0733-9364(1997)123:4(450).

Alzraiee, H., Zayed, T., \& Moselhi, O. (2014, January). Dynamic planning of construction activities using hybrid simulation. Automation in Construction, 49, 176-192. DOI: 10.1016/j.autcon.2014.08.011.

Ampofo, K. D. (2017). Reasons why Real Options Analysis (ROA) is not widely adopted in the mineral industry. The University of Queensland, Mining Engineering. Queensland: The University of Queensland.

Azaron, A., Sakawa, M., Tavakkoli-Moghaddam, R., \& Safaei, N. (2007, March). A Discrete-Time Approximation Technique for the Time-Cost Trade-Off in PERT Networks. RAIRO Operations Research, 41(1), 61-81. https://doi.org/10.1051/ro:2007005.

Botin, J., Del Castillo, M., \& Guzman, R. (2013). A real options application to manage risk related to intrinsic variables of a mine plan: a case study on Chuquicamata Underground Mine Project. Journal of the Southern African Institute of Mining and Metallurgy, 113(7), 583-592.

Brahm, F., \& Tarziján, J. (2015). Does complexity and prior interactions affect project procurement? Evidence from mining mega-projects. Internation Journal of Project Management, 33(8), 18511862. https://doi.org/10.1016/j.ijproman.2015.08.005.

Calp, M., \& Akcayol, M. (2018). Optimization of Project Scheduling Activities in Dynamic CPM and PERT Networks Using Genertic Algorithms. Journal of Natural and Applied Sciences, 22(2), 615-627. DOI: $10.19113 /$ sdufbed.35437.

Canadian Institute of Mining. (2011). Exploration Best Practices Guidelines. Retrieved from CIM: http://web.cim.org/standards/documents/Block465_Doc21.pdf

Chartered Institute of Building. (2008). Managing Risk of Delayed Completion in the 21st Century. Berkshire: $\mathrm{CIOB}$.

Connolly, E., \& Orsmond, D. (2011). The Mining Industry: From Bust to Boom. The Australian Economy in the 2000s (pp. 111-156). Sydney: Reserve Bank of Australia.

Del Castillo, F., \& Dimitrakopoulos, R. (2014). Joint effect of commodity price and geological uncertainty over the life of mine and ultimate pit limit. Mining Technology, 123, 207-219. https://doi.org/10.1179/1743286314Y.0000000069.

Dimitrakopoulos, R. G., \& Sabour, A. S. (2007). Evaluating mine plans under uncertainty: Can the real options make a difference? Resources Policy, 32(3), 116-125. https://doi.org/10.1016/j.resourpol.2007.06.003.

Dimitrakopoulos, R. G., \& Sabour, A. S. (2007). Evaluating mine plans under uncertainty: Can the real options make a difference? Resources Policy, 32(3), 116-125. 
Eldin, N. N., \& Senouci, A. B. (2004, December). Use of Genetic Algorithms in Resource Scheduling of Construction Projects. Journal of Construction Engineering and Management, 130(6), 869-877. https://doi.org/10.1061/(ASCE)0733-9364(2004)130:6(869).

Espinoza, D., \& Morris, J. W. (2013). Decoupled NPV: a simple, improced method to value infrastructure investments. Construction Management and Economics, 31(5), 471-496. https://doi.org/10.1080/01446193.2013.800946.

Espinoza, R. D. (2011). Contingency estimating using option pricing theory: closing the gap between theory and practice. Construction Management and Economics, 29(9), 913-927. https://doi.org/10.1080/01446193.2011.610328.

Guo, H., Zhu, K., Ding, C., \& Li, L. (2010, March). Intelligent optimization for project scheduling for the first mining face in coal mining. Expert Systems with Applications, 37(2), 1294-1301. https://doi.org/10.1016/j.eswa.2009.06.025.

Hall, J., \& Nicholls, S. (2007). Valuation of mining projects using option pricing techniques. The Finsia Journal of Applied Finance(4), 22-29.

Haque, M., Topal, E., \& Lilford, E. (2016). Evaluation of a mining project under the joint effect of commodity price and exchange rate uncertainties using real options valuation. The Engineering Economist, 62(3), 231-253. https://doi.org/10.1080/0013791X.2016.1217366.

Hillier, F. S., \& Lieberman, G. J. (1986). Introduction to Operations Research, Fourth Edition. Oakland: Holden-Day, Inc.

InfoMine USA, Inc. (2016). Mine and Mill Equipment Costs: An Estimator's Guide. Spokane Valley: InfoMine USA, Inc.

König, M., \& Beißert, U. (2009). Construction Scheduling Optimization by Simulated Annealing. 26th International Symposium on Automation and Robotics in Construction (pp. 183-190). Austin: IAARC.

Kenneth P. Green, T. J. (2017). Permit Times for Mining Exploration in 2016. Vancouver: Fraser Institute.

Kihn, S. (2015). What are Mine Surveyors in Canada Earning in 2015. Retrieved from Careermine: http://careerminer.infomine.com/what-are-mine-surveyors-in-canada-earning-in-2015/

Lau, E. K., \& NG, P. L. (2013). Review of Time-Cost Optimization Techniques in Construction Project Management. European Journal of Management, 13(3), 75-84. DOI: 10.18374/EJM-13-3.6.

Martens, A., \& Vanhoucke, M. (2017). A buffer control method for top-down project control. European Journal of Operational Research, 262(1), 274-286.

Marzoughi, F., Arthanari, T., \& Askarany, D. (2018, March). A Decision Support Framework for Estimating Project Duration under the Impact of Weather. Automation in Construction, 87, 287-296.

Muniappen, K., \& Genc, B. (2020). Dynamic simulation of an opencast coal mine: a case study. International Journal of Coal Science \& Technology, 7(1), 164-181. 
National Native Title Tribunal. (2009). Steps from Mineral Exploration to a Mine. Perth: Commonwealth Law Courts.

National Resources Canada. (2006). Canadian Minerals Yearbook. Ottawa: Minerals and Metals Sector, National Resources Canada.

PayScale, Inc. (2018). Geologist Salary (Canada). (PayScale, Inc.) Retrieved from PayScale: https://www.payscale.com/research/CA/Job=Geologist/Salary, Accessed on October 7, 2018

Renaud, M., \& Kumral, M. (2020). Planning a complex coal mine construction project under price cyclicality. Engineering Management Journal, 32(2), 120-129 https://doi.org/10.1080/10429247.2020.1718461.

Sabour, S., \& Wood, G. (2009). Modelling financial risk in open pit mine projects: implications for strategic decision-making. the Journal of The Southern African Institute of Mining and Metallurgy, 109, 169-175.

Samis, M., Martinez, L., Davis, G. A., \& Whyte, J. B. (2012). Using Dynamic DCF and Real Option Methods for Economic Analysis in NI43-101 Technical Reports.

Savageau, M., \& Kumral, M. (2018). Cash flow at risk valuation of mining project using Monte Carlo simulations with stochastic processes calibrated on historical data. The Engineering Economist, 63(3), 171-187. DOI: 10.1080/0013791X.2017.1413150.

Shepperd, J., Malone, W., \& Sweeny, K. (2008). Exploring Causes of the Self-Serving Bias. Social and Personality Psychology Compass, 2(2), 895-908. DOI: 10.1111/j.1751-9004.2008.00078.x.

Smith, C. (2014). Mines Act Permit Fees. Victoria: British Columbia Ministry of Energy and Mines.

Sykes, J. P. (2013). Beginning with the end in mind: strategies for rare earths miners \& explorers. Metal Pages Rare Earths . Shanghai: Greenfields Research.

Taylor, S. (1991). Asymmetrical Effects of Positive and Negative Events - The Mobilization Minimization Hypothesis. Psychological Bulletin, 110(1), 67-85.

Trench, A., \& Sykes, J. P. (2014). Perspectives on Mineral Commodity Price Cycles and their Relevance to Underground Mining. 12th AUSIMM Underground Operators' Conference (pp. 19-31). Adelaide: Australasian Institute of Mining and Metallurgy.

Ugurlu, O. F., \& Kumral, M. (2019). Optimization of drill bit replacement time in open-cast coal mines. International Journal of Coal Science \& Technology, 6(3), 399-407.

U.S. Securities and Exchange Commission. (2016). US Avg Export Price. Retrieved from U.S. Securities and Exchange Commission: https://www.sec.gov/Archives/edgar/data/1687187/000119312516807449/g272210g14k15.jpg

Wauters, M., \& Vanhoucke, M. (2014). Support vector machine regression for project control forecasting. Automation in Construction, 47, 92-106. http://dx.doi.org/10.1016/j.autcon.2014.07.014. 
617 Weaver, P. (2011). Why Critical Path Scheduling is Wildly Optimistic. PMICOS 2011 Annual Conference.

618 San Francisco: PMICOS.

619 Xiong, Y., \& Kuang, Y. (2008, February). Applying and Ant Colony Optimization Algorithm-Based

620 Multiobjective Approach for Time-Cost Trade-Off. Journal of Construction Engineering and

621 Management, 134(2), 153-156. https://doi.org/10.1061/(ASCE)0733-9364(2008)134:2(153).

622 Zhang, K., Nieto, A., \& Kleit, A. N. (2015). The real option value of mining operations using mean623 reverting commodity prices. Mineral Economics, 28(1), 11-22. DOI 10.1007/s13563-014-0048-6.

624 Zhou, J., Love, P. E., Wang, X., Teo, K. L., \& Irani, Z. (2013). A review of methods and algorithms for 625 optmizing construction scheduling. Journal of the Opeartional Research Society, 64(8), 1091-

626 1105. DOI:10.1057/jors.

627

628 


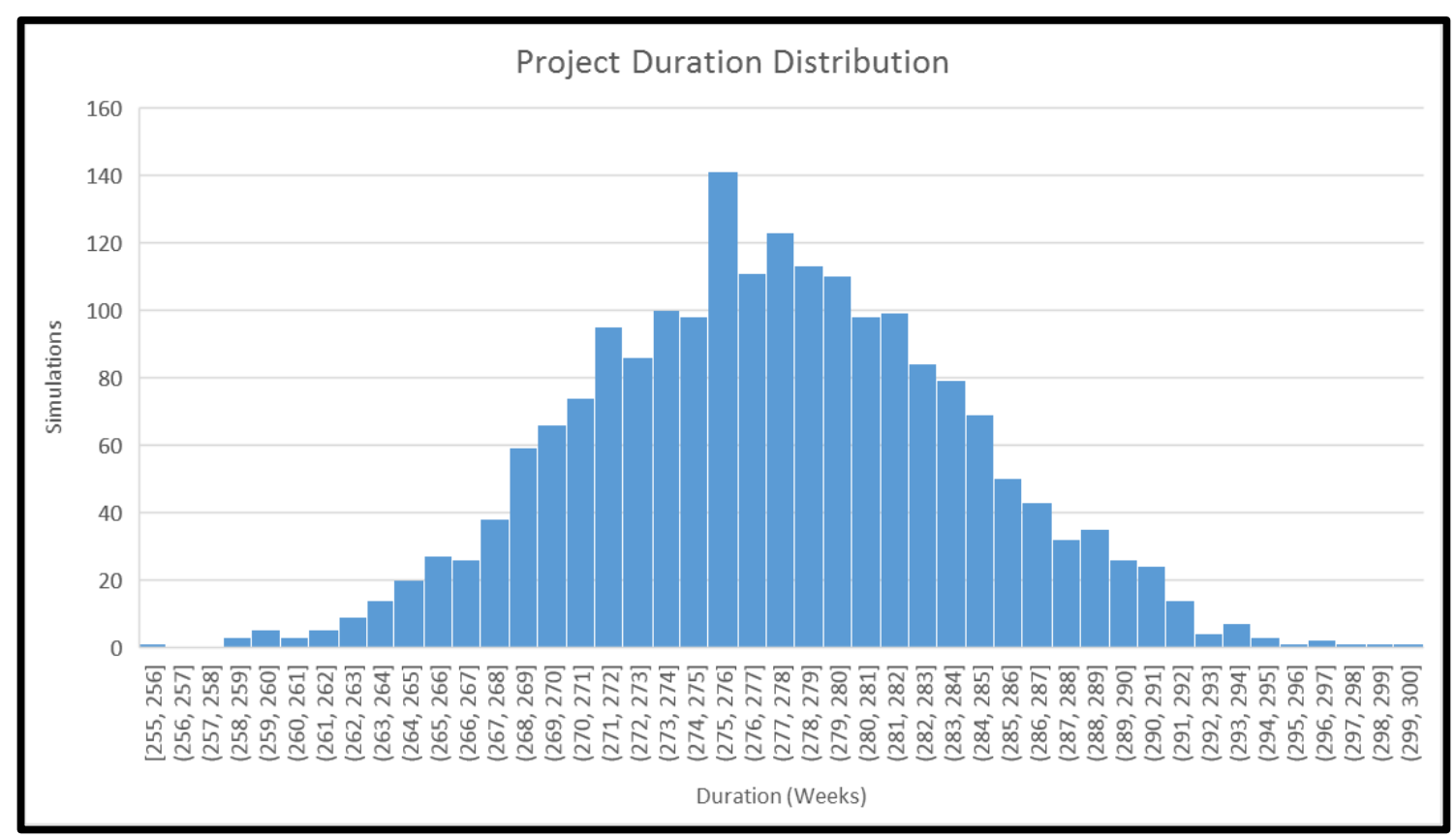




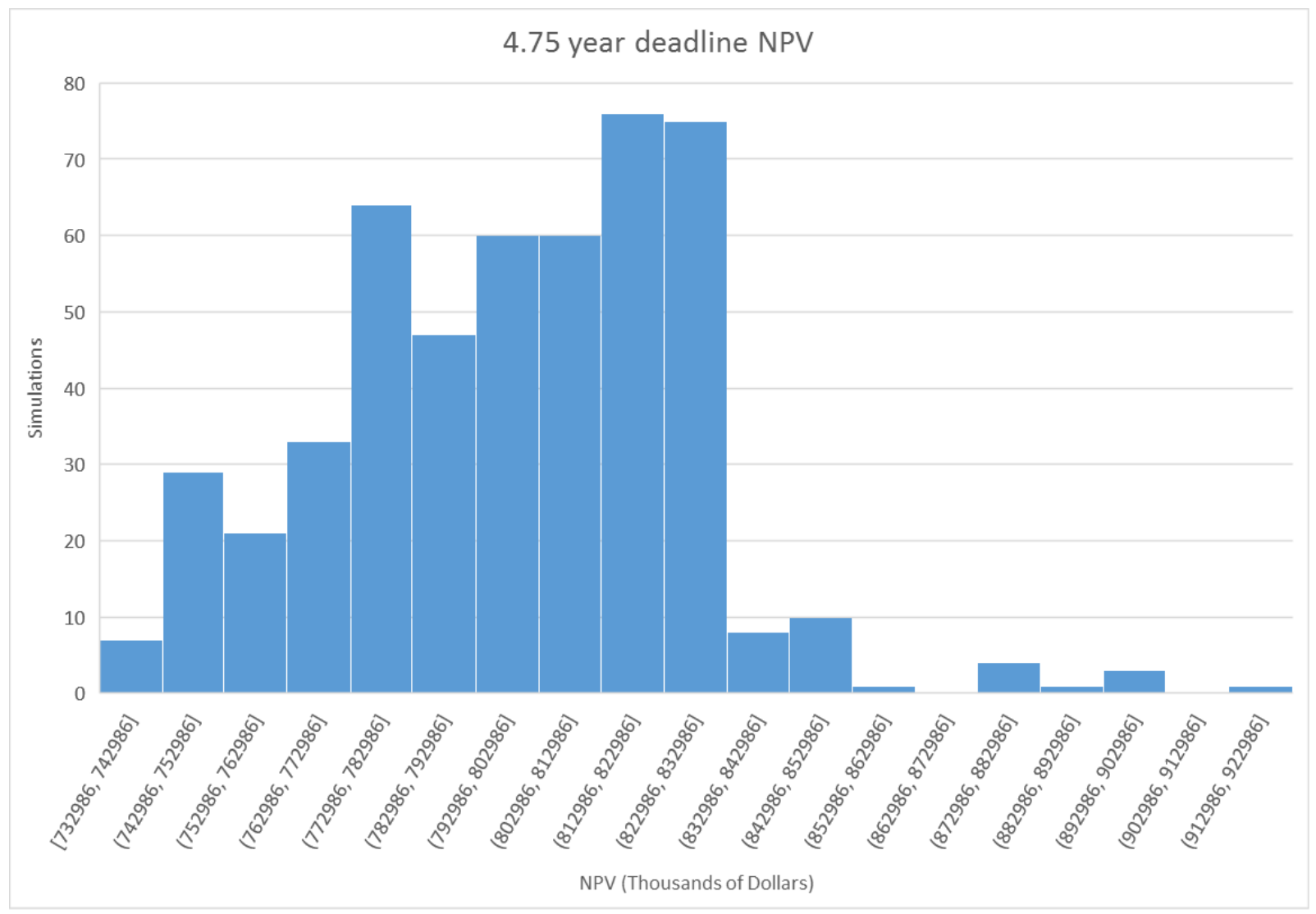

633

Fig. 2 Fixed duration (247-Week Deadline) Simulation Results

635

636

637

638

639

640

641

642

643

644

645

646

647 


\section{Appendix}

$649 \quad 1.1$ Activity List (with predecessors and sample duration)

\begin{tabular}{|c|c|c|c|c|c|c|c|}
\hline Act & Description & Dur & Predecessor & Act & Description & Dur & Predecessor \\
\hline 1 & Regional research & 5 & - & 1104 & Road finishing & 1 & 1102,1103 \\
\hline 2 & Regional airborne recon & 6 & 1 & 1111 & Planning/prep & 2 & 1054 \\
\hline 3 & Data analysis, area selection & 4 & 2 & 1112 & Foundation/structural construction & 10 & 1111 \\
\hline 4 & Obtain exploration license & 24 & - & 1113 & Water/power/HVAC & 10 & 1112,1052 \\
\hline 5 & Ground recon, surveying & 12 & 6 & 1114 & Exterior construction & 6 & 1112 \\
\hline 6 & Exp. equipment delivery & 10 & 3,4 & 1115 & Interior construction & 6 & 1114,1113 \\
\hline 7 & Map design & 4 & 5 & 1116 & Admin finishing & 2 & 1115 \\
\hline 8 & Surface sampling & 6 & 6 & 1121 & Foundation/structural construction & 8 & 108 \\
\hline 9 & Stripping 1 & 2 & 7 & 1122 & Exterior construction & 6 & 1121 \\
\hline 10 & Stripping 2 & 8 & 9 & 1123 & Water/HVAC systems & 8 & 1122 \\
\hline 11 & Exploration drilling & 12 & 9 & 1124 & Power systems & 8 & 1122 \\
\hline 12 & Pitting & 8 & 9 & 1125 & Mineral processing equipment installation & 12 & $123,1123,1124$ \\
\hline 13 & Mapping & 4 & 12,15 & 1126 & Plant finishing & 2 & 1125 \\
\hline 14 & Resource estimation & 6 & 16 & 1131 & Planning/staking/prep & 2 & 1054 \\
\hline 15 & Detail drilling & 16 & 10,11 & 1132 & Foundation & 10 & 1131 \\
\hline 16 & Pilot testing & 12 & 15,17 & 1133 & Structural construction & 12 & 1132 \\
\hline 17 & Bulk sampling & 6 & 12 & 1134 & Water systems & 8 & 1052,1133 \\
\hline 18 & Financial analysis & 6 & 14,21 & 1135 & Power systems & 6 & 116,1133 \\
\hline 19 & Feasibility study & 12 & 13,18 & 1136 & Equipment installation & 20 & 1135,2001 \\
\hline 21 & Sample testing & 12 & 8,17 & 1137 & Maintenance finishing & 6 & $1136,1134,1139$ \\
\hline 202 & Design scheduling & 1 & 19 & 1138 & Shop testing & 4 & 1137 \\
\hline 203 & Mining method planning & 7 & 202 & 1139 & Exterior construction & 8 & 1133 \\
\hline 204 & Production rates \& targets & 2 & 203 & 114 & Ordering mining equipment & 4 & 106 \\
\hline 205 & Mine service planning & 8 & 202 & 115 & Transportation/assembly of mining equipment & 24 & 1104,114 \\
\hline 206 & Mining transport planning & 8 & 202 & 116 & Energy supply & 8 & 104 \\
\hline 207 & Mine sequencing & 7 & 204,206 & 117 & Mineral labor recruitment & 10 & 106 \\
\hline 208 & Production \& economic model & 5 & 205,207 & 118 & Ordering mineral processing equipment & 4 & 106,108 \\
\hline 209 & Plan optimization & 2 & 208 & 119 & Blasting material supply & 4 & 109 \\
\hline 104 & Obtaining operating license & 10 & 208 & 120 & Testing the mine equipment & 2 & 115,116 \\
\hline 1051 & Clearing & 2 & 209,104 & 1211 & Survey/staking & 2 & 120 \\
\hline 1052 & Water management & 4 & $107,1053,1000$ & 1212 & Drilling/loading first bench & 6 & 1211,119 \\
\hline 1053 & Secondary survey/staking & 2 & 1051 & 122 & Processing equipment supply and transportation & 12 & 118,1104 \\
\hline 1054 & Ground prep & 4 & 1053,1000 & 123 & Assembly of mineral processing equipment & 16 & 122 \\
\hline 106 & Obtaining financing & 10 & 104 & 124 & Training of the mineral processing workers & 8 & 117,125 \\
\hline 107 & Water supply to the site & 10 & 104 & 125 & Testing the mineral processing equipment & 2 & $1126,1123,116$ \\
\hline 108 & Processing plant planning & 6 & 1052,1054 & 126 & Overburden removal & 52 & $1001,1212,1138,1116$ \\
\hline 109 & Explosive storage construction & 12 & 1054 & 1000 & Construction equipment delivery & 8 & 1104 \\
\hline 1101 & Clearing/prep & 6 & 104 & 1001 & Labor training & 8 & 120,117 \\
\hline 1102 & Ditching & 3 & 1101 & 2000 & Ordering maintenance equipment & 4 & 106 \\
\hline 1103 & Surfacing & 3 & 1101 & 2001 & Delivery of maintenance equipment & 8 & 2000,1104 \\
\hline
\end{tabular}

650

651

Adapted from (Renaud \& Kumral, 2020) 


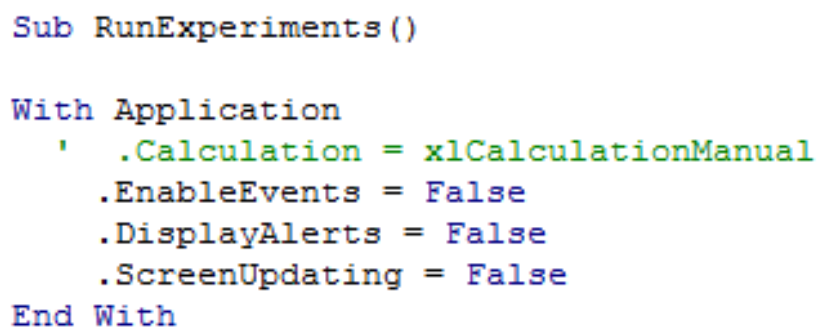




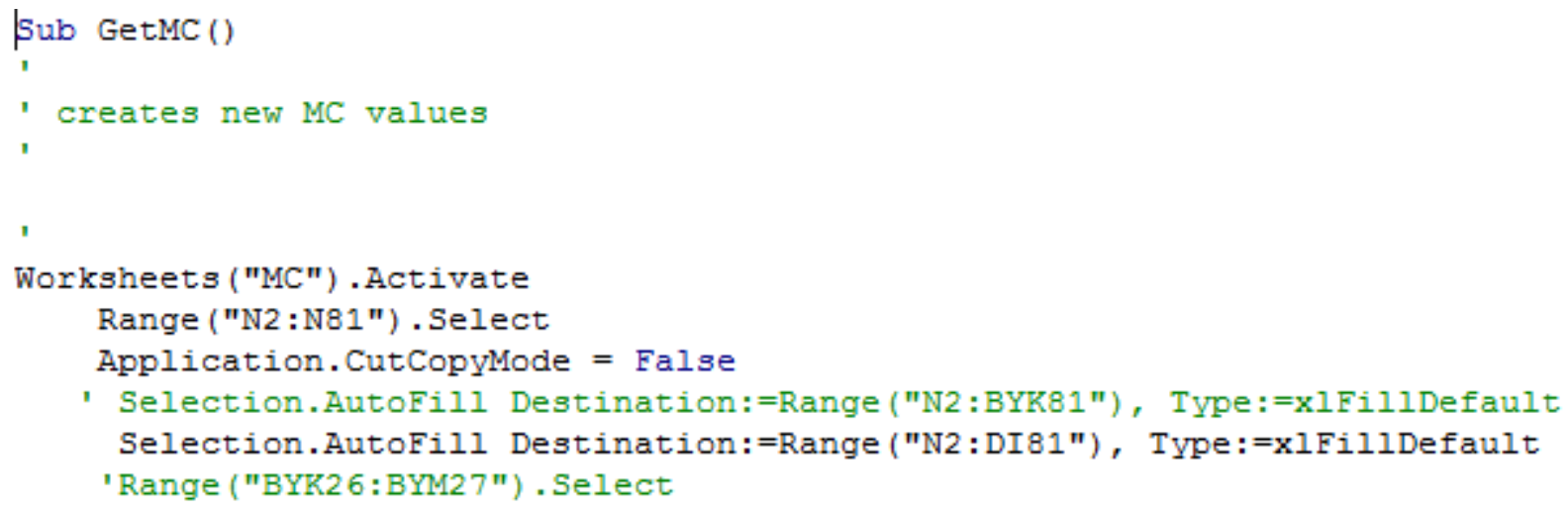

654

Sub ResultsPaste ()

Dim NextCol As Long

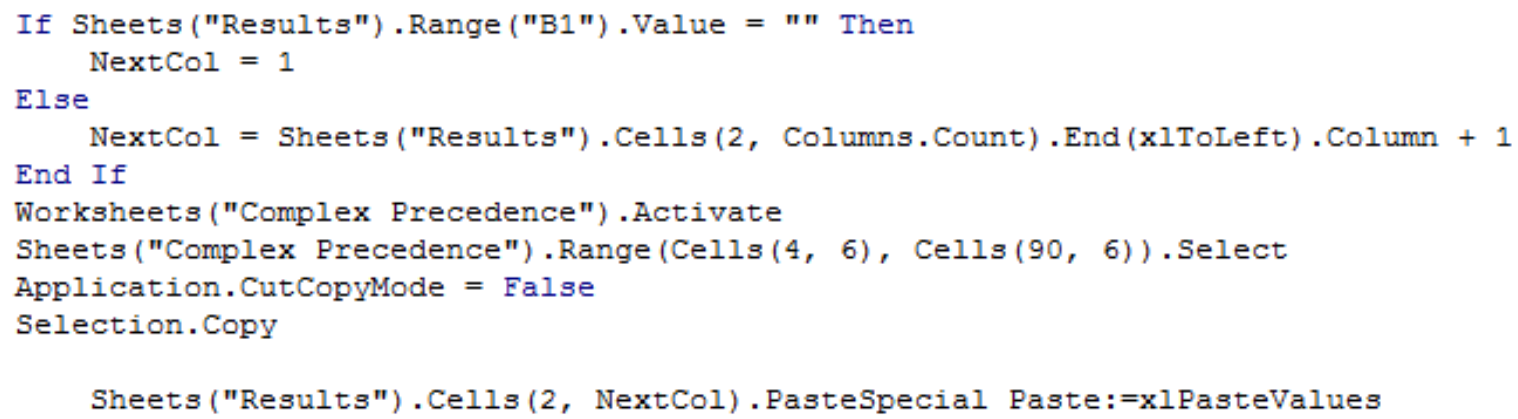

656

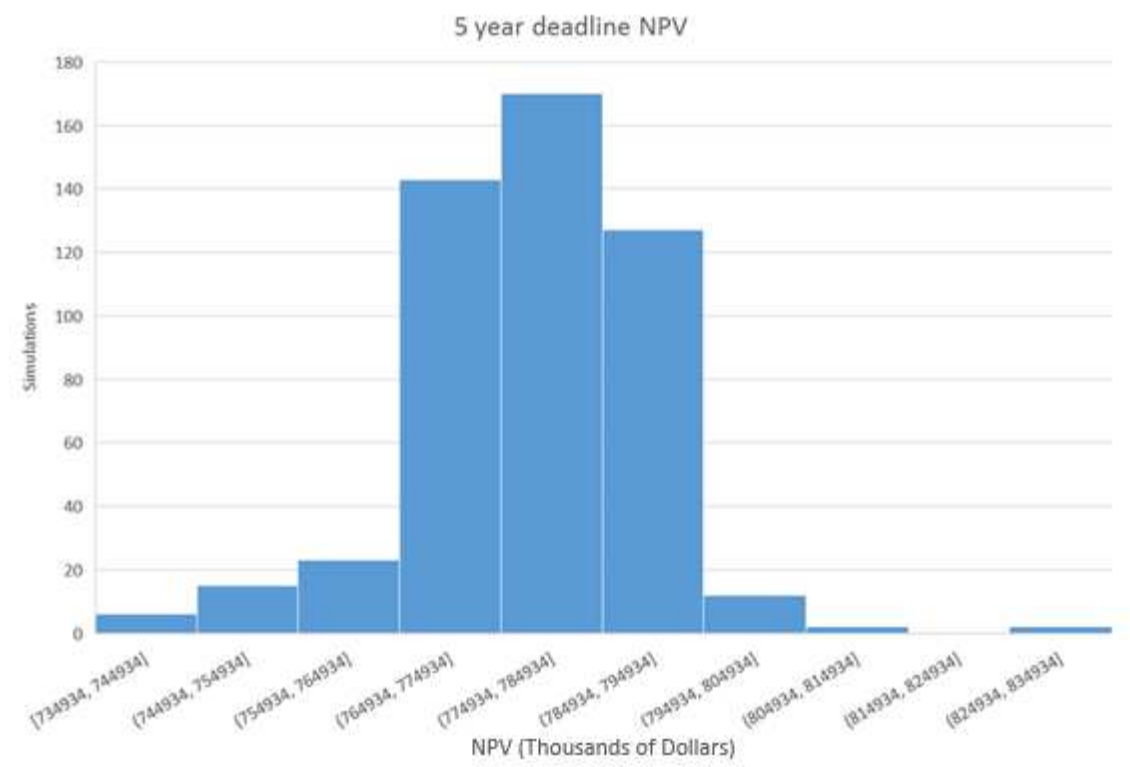




\subsection{5 year deadline NPV}

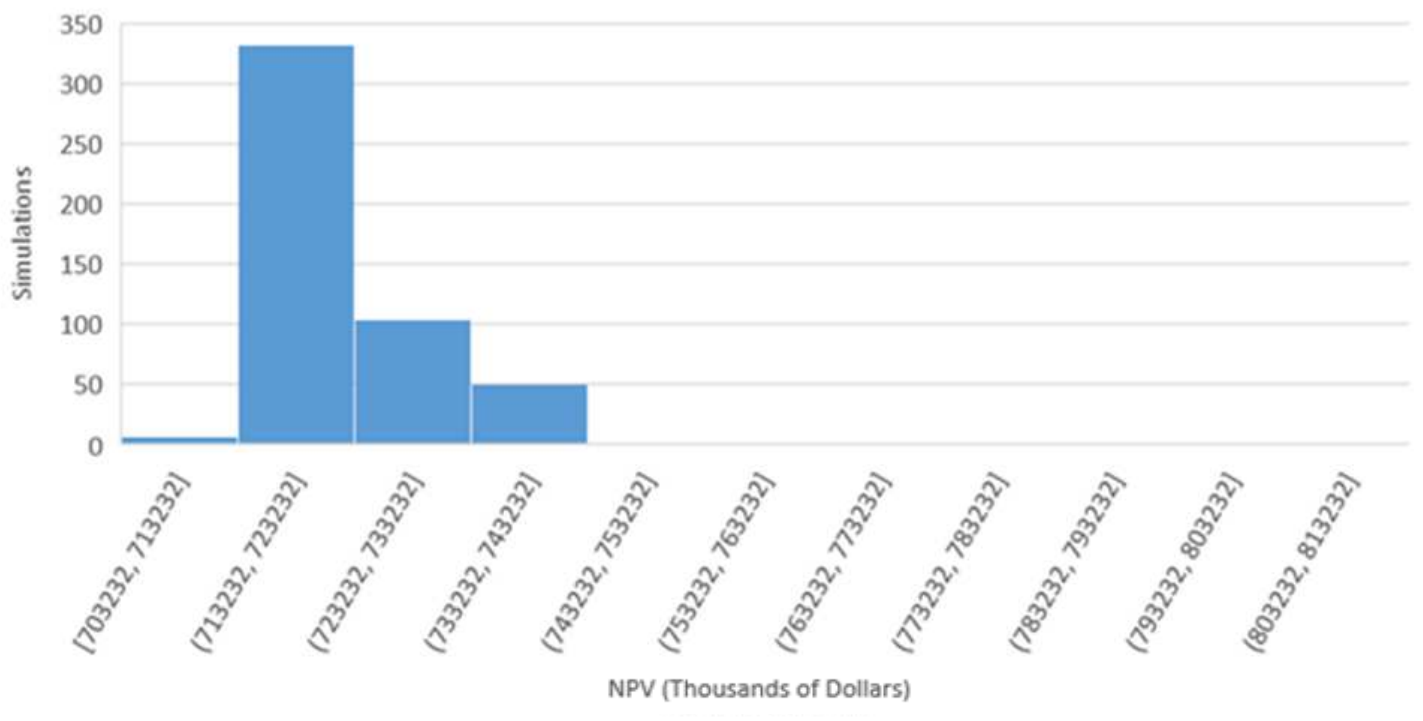

659

660

661

662

663

664

665

666

667

668

669

670

671

672

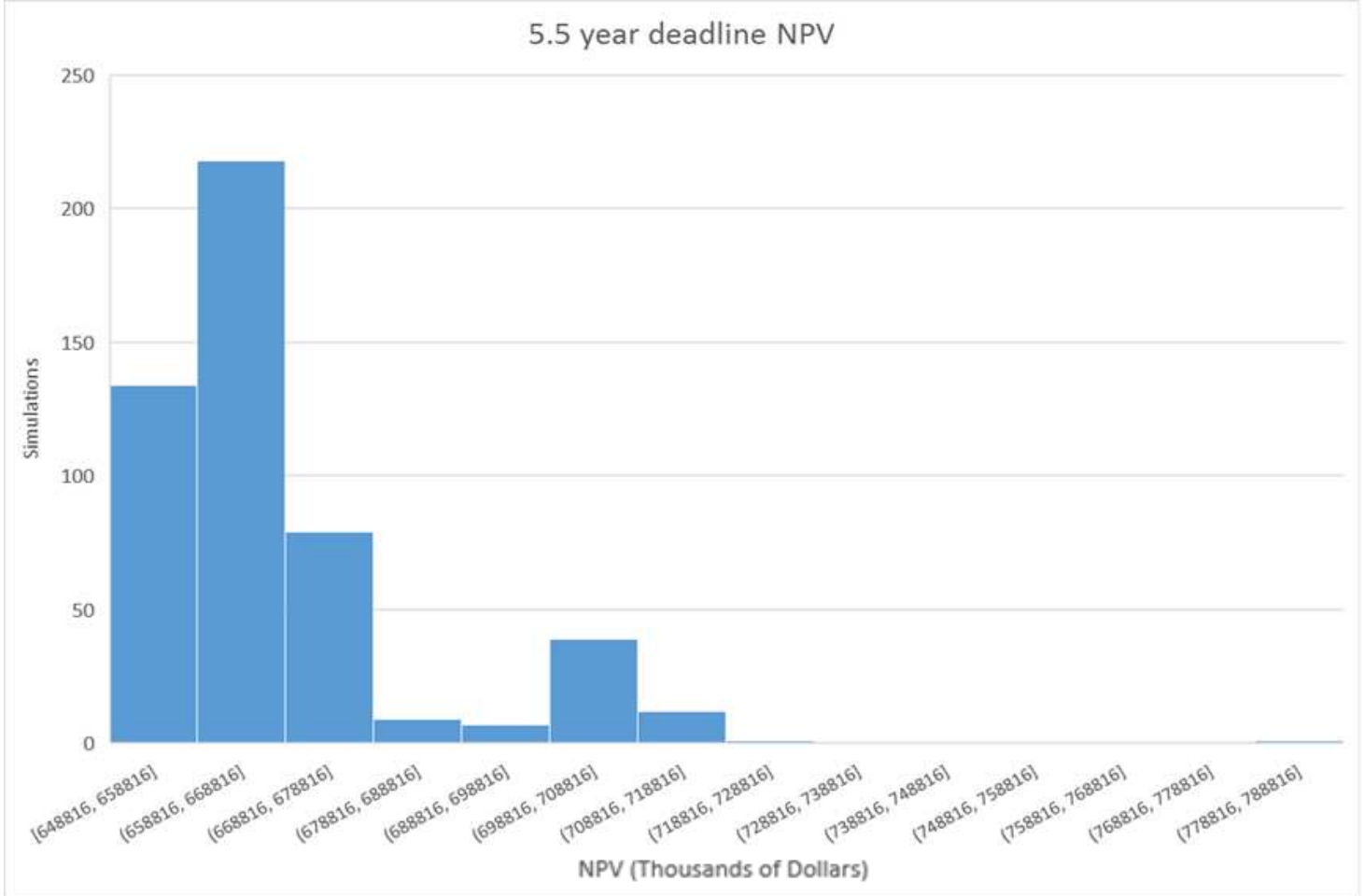

673 
$674 \quad 1.4$ Activity Network Diagram

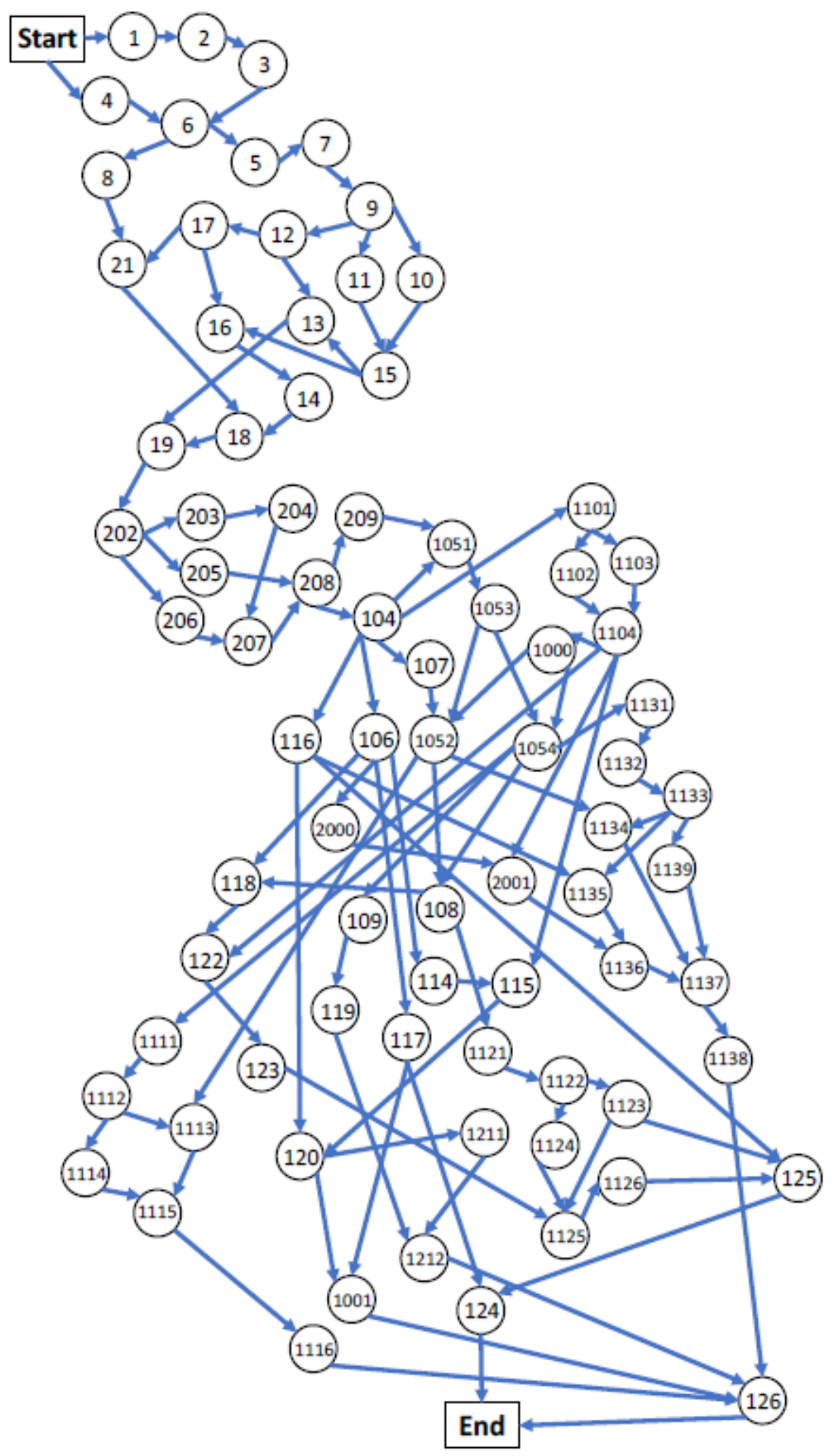


Figures

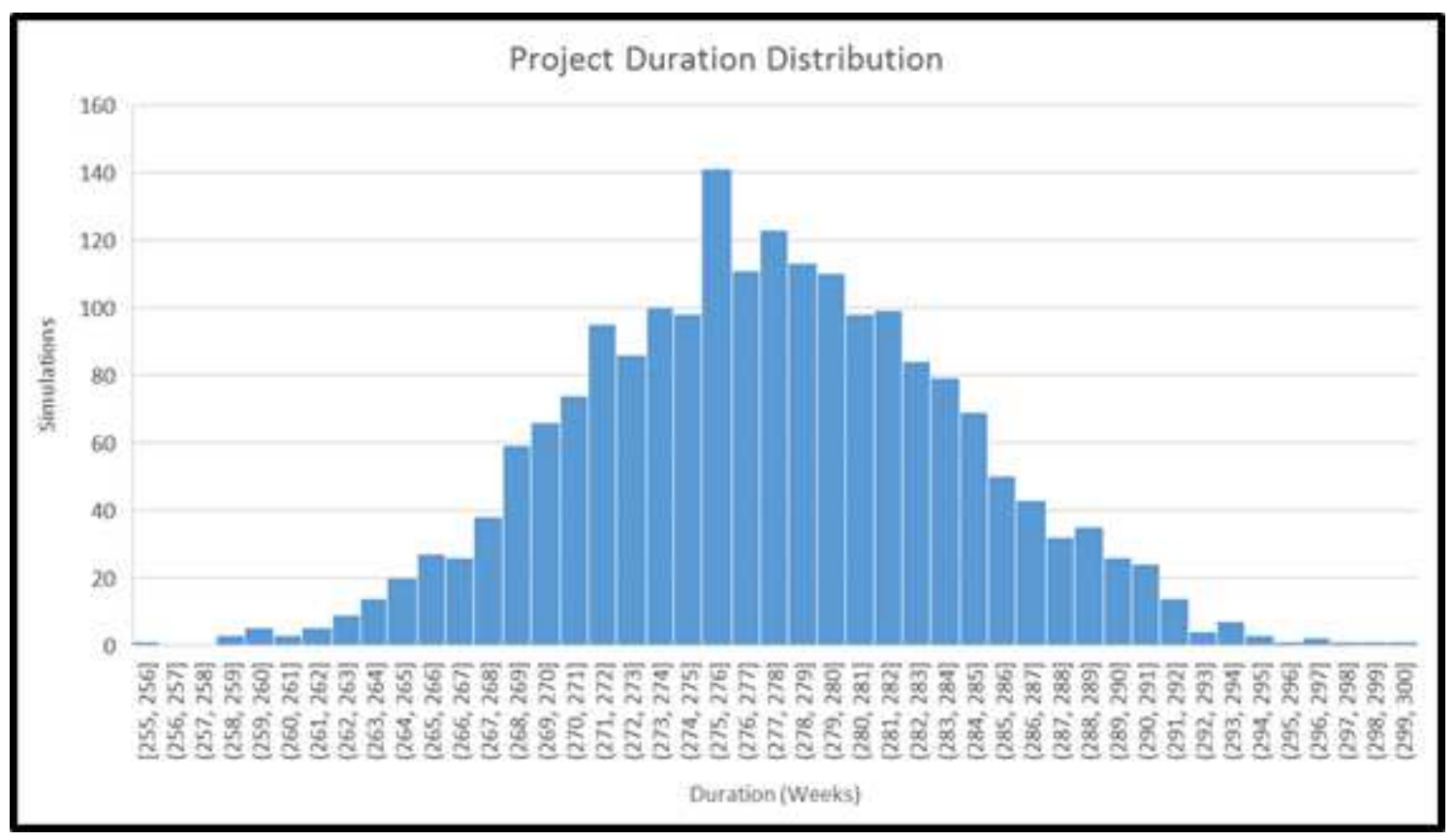

Figure 1

Fixed Cost (\$987.99) Simulation Results

4.75 year deadline NPV

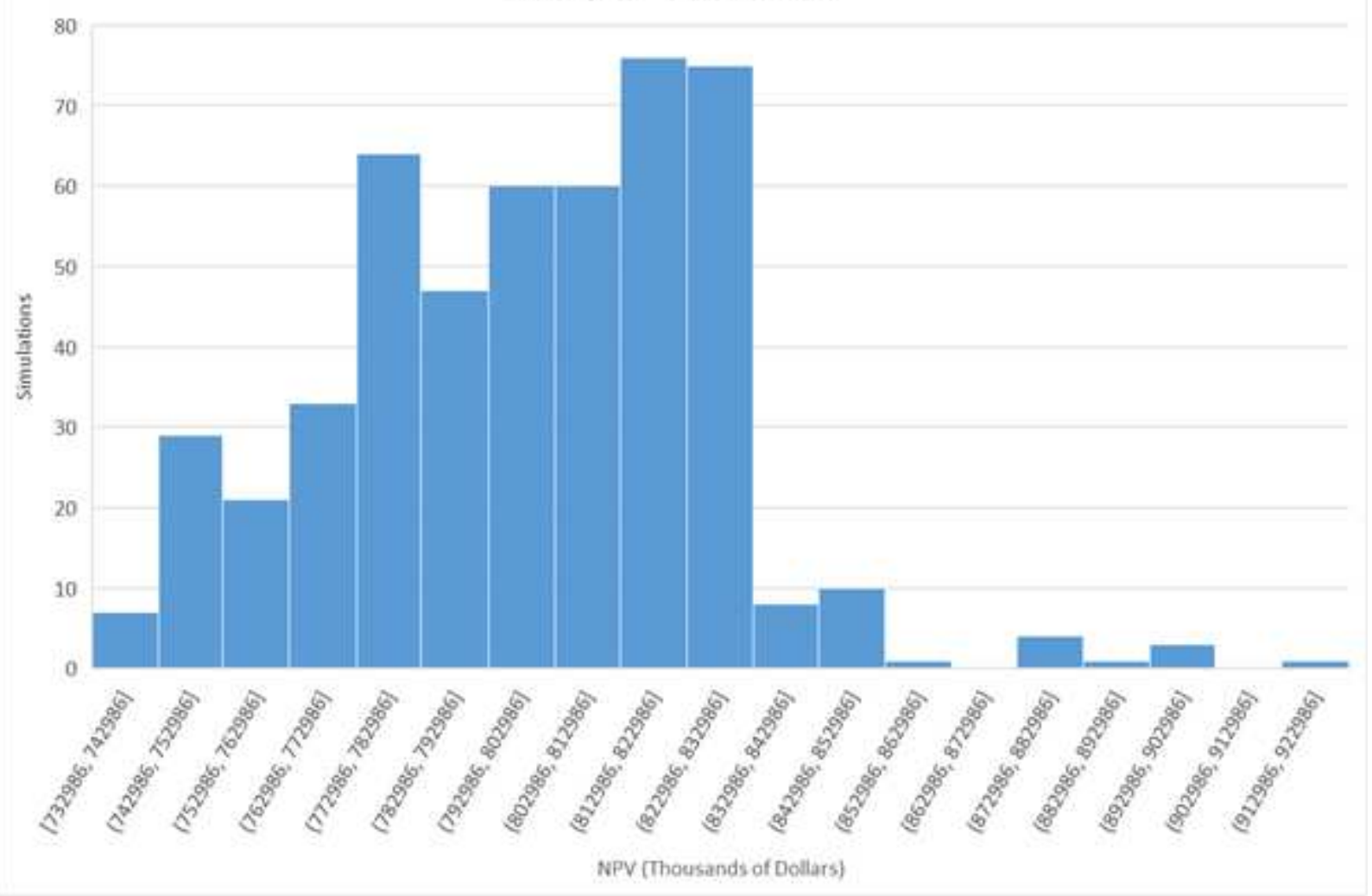

Figure 2 
Fixed duration (247-Week Deadline) Simulation Results 